\title{
Anti-jugular vein thrombotic effect of Morinda citrifolia $L$. [noni] in male SD rats
}

\section{${ }^{1}$ Funmi Ayanbule, ${ }^{2}$ Guodong Li, ${ }^{1}$ Lin Peng, ${ }^{1}$ Jacob Nowicki, ${ }^{1}$ Gary Anderson, ${ }^{1}$ Mian-Ying Wang}

${ }^{1}$ University of Illinois College of Medicine at Rockford, Department of Pathology, 1600 Parkview Avenue, Rockford, IL 61107, USA; ${ }^{2}$ Zhengzhou University, Department of Bioengineering, 100 Science Road, Zhengzhou, Henan 450001, China, PRC

Corresponding author: Mian-Ying Wang, MD, University of Illinois College of Medicine at Rockford, Department of Pathology, 1601 Parkview Avenue, Rockford, IL 61107, USA

Submission date: March 03, 2011; Acceptance date: September 21, 2011; Publication date: September 22, 2011

Running title: Anti-jugular vein thrombotic effect of noni juice (NJ)

\begin{abstract}
$\underline{\text { Abstract }}$
Background: Venous thromboembolism (VTE) is a common and serious medical condition, which is estimably responsible for more than 300,000 hospital admissions annually in the USA. Pulmonary embolism (PE) is a major complication of VTE, which contributes to $12 \%$ death of hospitalized patients. Heparin is the most common anti-coagulant, but severe allergic reactions, bleeding, and thrombocytopenia limit its use. Thus, seeking a botanical, nontoxic antithrombotic alternative is an interesting area. Morinda citrifolia L. [noni] is a medicinal plant used in folk remedies by Polynesians for over 2,000 years. It has been reported to have a broad range of therapeutic and preventive effects. The bioactivities of NJ have been continuously discovered with antioxidative, anti-inflammatory, analgesic, and immune modifying activities. Our novel hypothesis is whether $\mathrm{NJ}$ has an anti-venous thrombotic effect in rodents. To examine our hypothesis, this study was designed to examine the anti-thrombotic effect of $\mathrm{NJ}$ on the jugular vein thrombosis model induced by ferric chloride in SD rats.
\end{abstract}

Material and Methods: NJ and placebo used in this study were donated by Morinda Holding Inc. NJ was formulated with grape juice and blue berry juice. Placebo was prepared by using the same procedure of NJ preparation, but without NJ in it. Thirty-six male SD rats were divided into six groups. Anti-venous thrombotic activities of 5\% NJ, $10 \% \mathrm{NJ}$, heparin, and $10 \% \mathrm{NJ}$ plus heparin were examined and compared with the positive and blank controls. Thrombosis was induced by application of a filter paper soaked in $50 \%$ ferric chloride on the right jugular vein. A 
2-cm fragment of the occluded vein (thrombus) was removed and weighed after 1-hour maturation. Blood samples were collected for platelet count, aPTT, and PT tests.

Results: The weight of a 2-cm fragment of normal jugular vein was $9.9 \pm 2.1 \mathrm{mg}$, while the weight of the occluded vein in positive controls was $30.7 \pm 12 \mathrm{mg}$ [p=0.001], $24.7 \pm 6.5 \mathrm{mg}$ in heparin $[\mathrm{p}=0.16], 25.5 \pm 6.5 \mathrm{mg}$ in $5 \% \mathrm{NJ}[\mathrm{P}=0.15], 20.0 \pm 5 \mathrm{mg}$ in $10 \% \mathrm{NJ}[\mathrm{P}=0.04]$, and $16.1 \pm$ $5.0 \mathrm{mg}$ in heparin plus $10 \% \mathrm{NJ}[\mathrm{P}=0.02]$, respectively. The activity of aPTT was significantly increased in heparin, $60.0 \pm 10.0 \mathrm{sec}$ [p=0.002] compared with $16.83 \pm 4.9 \mathrm{sec}$ in blank control. There was a significant increase in $5 \% \mathrm{NJ}$ [34.24 $\pm 9.6 \mathrm{sec}, \mathrm{p}=0.01]$, a slight increase in $10 \% \mathrm{NJ}$ [24.0 $\pm 5.4 \mathrm{sec}, \mathrm{p}=0.06]$. The activity of PT was significantly increased in heparin group only [36.52 $\pm 3.0 \mathrm{sec}$ vs $26.85 \pm 0.4 \mathrm{sec}$ in blank control, $\mathrm{p}=0.01$ ). There was no significant change in NJ groups. Clearly, the reduced thrombus weight by heparin may be partially due to the activation of aPTT and PT. The slight inhibition of NJ on aPTT activity may explain the possible additive antithrombotic effect of $\mathrm{NJ}$ with heparin. The platelet count was slightly reduced to 775,700 in the heparin group compared with blank control, there was no changes observed in other groups.

Conclusion: NJ has an anti-jugular vein thrombotic effect and a possible additive antithrombotic effect with heparin by activating aPTT without induction of thrombocytopenia. We wonder whether NJ has an anti-platelet function activity. The mechanisms for anti-venous thrombotic effects of NJ needs further study.

Key words: Morinda citrifolia L. [noni], noni juice (NJ), jugular vein thrombosis, heparin, antithrombosis, anticoagulant, activated partial thromboplastin time [aPTT], prothrombin time [PT].

\section{Background:}

Venous thromboembolism (VTE) is a common and serious medical condition. It has been reported to be responsible for more than 300,000 hospital admissions per year in the United States [1]. Of these patients, approximately one-third present with clinical symptoms of acute pulmonary embolism (PE) and two-thirds with deep venous thrombosis (DVT) [2]. PE is the major complication of VTE, which contributes to death in about $12 \%$ of hospitalized patients in the USA [3]. The array of illnesses produced by VTE includes suddenly death from PE, longterm post-thrombotic syndrome, hospitalization, complications from the anticoagulant therapy such as heparin, and the psychological impact of a potentially chronic recurrent illness [4]. Heparin is a sulfated polysaccharide with a molecular weight range of 3,000 to 30,000 Da. It produces its major anticoagulant effect by inactivating thrombin and an activated clotting factor $\mathrm{X}$ through an anti-thrombin-dependent mechanism [5]. A significant therapeutic drug being used for DVT is unfractionated heparin and low-molecular-weight heparin [6]. Recent registries and cohort studies suggest that approximately $10 \%$ of all patients with acute PE die during the first 1 to 3 months after diagnosis. Overall, $1 \%$ of all patients admitted to hospitals die of acute PE, and $10 \%$ of all hospital deaths are PE-related. These facts emphasize the need to better apply our 
knowledge on the pathophysiology of the disease, recognize the determinants of death or major adverse events in the early phase of acute PE, and most importantly, identify those patients who necessitate prompt medical, surgical, or interventional treatment to restore the patency of the pulmonary vasculature [7-8]. By inactivating thrombin, heparin not only prevents fibrin formation, but also inhibits thrombin-induced activation of platelets and clotting factors $\mathrm{V}$ and VII (9). An important limitation of unfractionated heparin is the lack of an oral formulation, and an unpredictable anti-coagulant effect due to variable, non-specific binding to plasma proteins [10]. The severe side effects include heparin-induced thrombocytopenia, severe bleeding, and osteopenia [11]. In addition, aspirin has also been used widely in preventing thrombosis in spite of its weak anti-platelet effect, adverse gastrointestinal effects, which involve tract and epigastric discomfort, and acute mucosal erosion with chronic peptic ulceration and bleeding [12-13]. It is therefore important to provide a cost-effective, nontoxic, and natural product for the prevention of VTE, or as an adjuvant therapy for this clinical problem. Hence, an alternative and safer antiplatelet treatment with fewer side effects is definitely needed [14-15].

Morinda citrifolia L. [noni] is a medicinal plant that has been used in folk remedies by Polynesians for over 2000 years [16-19]. It has been reported to have a broad range of therapeutic effects such as anti-oxidative, anti-inflammatory, antihistamine, antifungal, antibiotic, anticancer, and analgesic properties [20]. It has also been reported to have antithrombotic properties, but the mechanism remains unknown [21]. In previous studies, it was demonstrated that NJ made from Tahitian noni fruits by Morinda Holding Inc. is able to inhibit inflammatory reactions, scavenge reactive oxygen free radicals, quench lipid hydroperoxides, and inhibit Cox1, Cox-2, and 5-LOX activities [22-26]. Figure 1 shows a Tahitian noni tree on the beach. This study examined the preventive effect of $\mathrm{NJ}$ and its additive and/or synergistic effect with heparin on jugular vein thrombosis induced by ferric chloride, as well as its possible mechanistic activities.

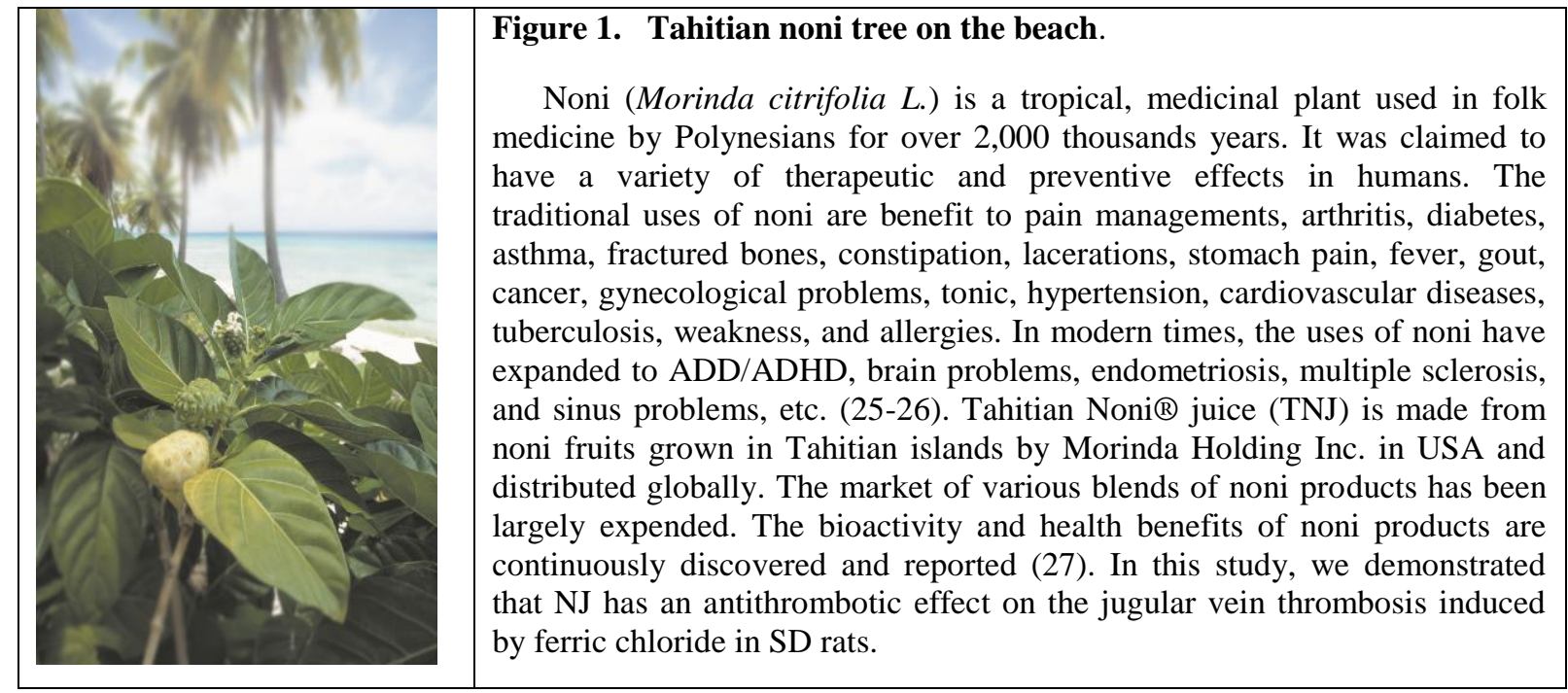

Various animal models are available for screening the efficacy of antithrombotic agents. But, $\mathrm{FeCl} 3$ induced endothelial dysfunction, platelet activation, clotting and inconsistent blood flow, and intravascular thrombus formation mimics closely the human pathological condition. As an oxidant, $\mathrm{FeCl} 3$ induced intravascular thrombosis is a simple and reliable model to evaluate the 
efficacy of antithrombotic agents. This model has been used in various animal species including mice, rats and guinea pigs. The jugular vein thrombosis was generally selected for antithrombotic screening because it was easily approachable via a midline cervical incision without any mortality (27).

\section{Materials and Methods:}

NJ and placebo: Noni juice (NJ) made from noni fruits grown in Tahiti was prepared and kindly donated by Morinda Holding Inc [28]. NJ was formulated with grape juice and blue berry juice. Placebo was prepared by R \& D Department of Morinda Holding Inc. by using the same procedure of NJ preparation, but without NJ in it. NJ used in this study was diluted into 5\% NJ and $10 \% \mathrm{NJ}$ with drinking water and then put into a clean glass drinking bottle. The fresh prepared NJ and 10\% placebo in positive control group was changed on the daily basis. The amount of the NJ and placebo consumed was recorded. Other reagents were purchased from Sigma Chemical Inc. SD rats were purchased from Charles River Animal Laboratory.

Animals' maintenance: Thirty-six 6-weeks old male Sprague-Dawley [SD] rats were purchased from Charles River Animal Laboratory [Wilmington, MA, USA]. The animals were maintained in accordance with the recommendation of the "Guidelines for the Care and Use of Laboratory Animals". All animals were housed in a room maintained at $25^{\circ} \mathrm{C}$, and with a $12 \mathrm{~h}$ photoperiod. They were fed a laboratory chow diet and water ad libitum. The experimental design for these tests was approved by the Institutional Ethics Review Committee for animal experiments at the UIC College of Medicine at Rockford.

Experimental design: The experimental design is schematically described in Scheme 1.

\section{Scheme 1.}

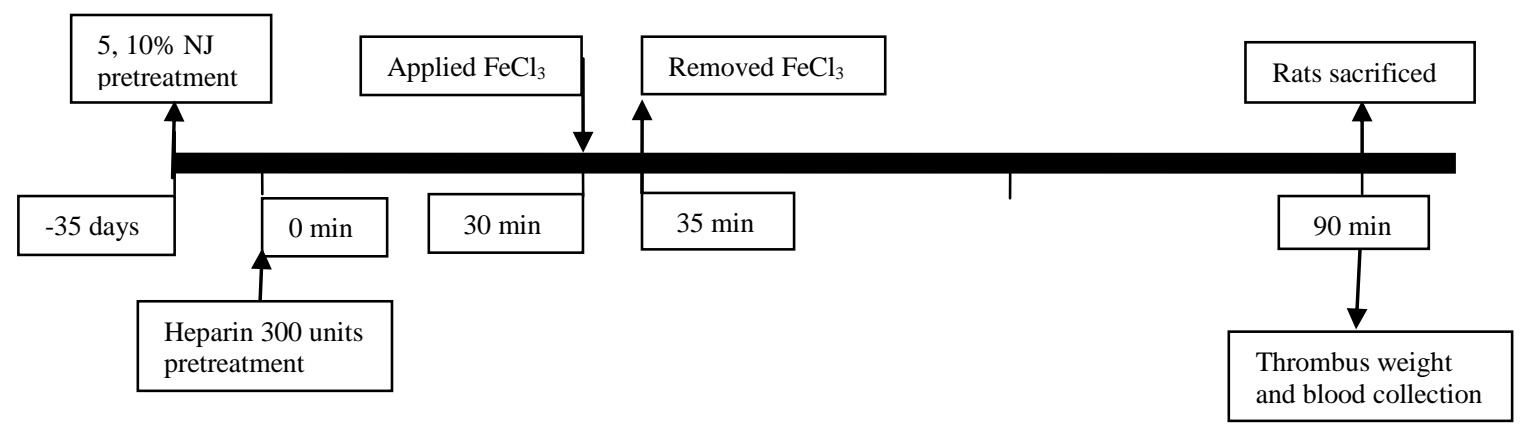

Scheme 1. Time course of the experiment. Two doses of NJ were pre-administered in drinking water for 35 days. Heparin was administrated at 0 minute for $30 \mathrm{~min}$, then ferric chloride was applied onto the exposed jugular vein for $5 \mathrm{~min}$ to induce thrombosis. The thrombus was removed and weighted after 1 hour maturation and weighted. The blood samples were collected for platelet count, aPTT, and PT tests.

The animals in the blank control were fed a laboratory chow diet and water, without any treatments, the animals in the positive control group were pretreated with $10 \%$ placebo, then 
treated with ferric chloride; the animals in the heparin groups were not received any pretreatments; and the pretreated rats in $\mathrm{NJ}$ group were supplied with $5 \%, 10 \% \mathrm{NJ}$, and the animals in the combination of $\mathrm{NJ}$ plus heparin group were received $10 \% \mathrm{NJ}$ in drinking water for 35 days before surgery. Phase 1 study examined the preventive effect of $5 \% \mathrm{NJ}$ and $10 \% \mathrm{NJ}$ in drinking water on thrombosis induced by ferric chloride on the right jugular vein compared to the blank control and positive control. Phase 2 study examined whether $10 \% \mathrm{NJ}$ had an additive and/or synergistic antithrombotic effect with heparin. The NJ concentration used in the combination treatment of Phase 2 study was determined by the effective dose of NJ that caused the significant thrombus weight reduction in Phase 1 study. The procedure involved in this study was approved by the University of Illinois' Biologic Resource Committee [BRC].

Induction of jugular vein thrombosis: The animals were pretreated with $\mathrm{NJ}$ or placebo in drinking water for 5 weeks prior to the start of thrombosis assay. The animals in heparin group received $300 \mathrm{U} / \mathrm{kg}$ intravenously $30 \mathrm{~min}$ prior to thrombus induction. All animals were anesthetized with an intraperitoneal injection of pentobarbital sodium [50 mg/kg]. The right neck was cleaned with alcohol pads, followed by a transverse cervical incision. The internal jugular vein was identified and a $2-\mathrm{cm}$ segment was isolated with $2-0$ nylon sutures. A $5 \times 5 \mathrm{~mm}$ filter paper soaked in ferric chloride $[50 \% \mathrm{w} / \mathrm{w}]$ was applied to the external surface of the vein for 5 min, and then removed as previously described [29]. The skin layer was closed with stapler and the animals were returned to their cages. After $1 \mathrm{~h}$, the rats were re-anaesthetized and sacrificed by intra-cardiac puncture for blood sample collection. Blood samples were collected into specific plastic tubes provided by a clinical lab for platelet count, aPTT and PT tests [30]. Samples were immediately centrifuged at $2500 \mathrm{rpm}$ for $10 \mathrm{~min}$ to obtain plasma and stored at $-20^{\circ} \mathrm{C}$ until analyzed. Analysis of aPTT was performed at the University of Illinois Veterinary Diagnostic Laboratory, Urbana, IL, while analysis of PT and platelet count was carried out at the University of Illinois Family Health Center Laboratory, Rockford, IL. After blood collection, the neck incision was examined and the presence or absence of a thrombus was noted. The 2-cm segment of occluded vein [thrombus] was harvested and the wet weight was determined on an analytical balance. The effective dose of $10 \%$ NJ was determined in the Phase-1 study. Six animals were pretreated with $10 \% \mathrm{NJ}$ for 5 weeks, and heparin $300 \mathrm{U} / \mathrm{kg}$ was administered by i.v 30 min prior to thrombus induction. The thrombus was induced by the same method applied in Phase 1. Thrombus wet weight was also determined and blood samples were analyzed for platelet count, aPTT, and PT determinations [31-32].

ANOVA tests were used in statistical evaluation of the data, which are given as mean \pm SD and a value of $\mathrm{p}<0.05$ was considered as significant [33].

\section{Results:}

The result from this study indicated that the jugular vein thrombosis was successfully induced by oxidative ferric chloride compared with blank control. The weight of a 2-cm of normal jugular segment in untreated control was measured as $9.90 \pm 2.10 \mathrm{mg}$ in weight. Thrombosis were also successfully induced in all animals of the positive control, pre-treated groups and the frequency of thrombus and thrombus weight in each group are presented in Table 1. 
Table 1. Effect of NJ and heparin on frequency and weight of thrombi induced in jugular vein of rats.

\begin{tabular}{|l|c|c|c|}
\hline Treatment & $\mathrm{t} / \mathrm{n}$ & Thrombus wt [mg] & $P$ value \\
\hline Blank control & $0 / 6$ & $9.90 \pm 2.10$ & \\
\hline Fecl3 & $6 / 6$ & $30.68 \pm 11.98$ & $0.001^{* * *}$ \\
\hline Heparin [300 U/kg] only & $6 / 6$ & $24.72 \pm 6.50$ & 0.16 \\
\hline $5 \% \mathrm{NJ}$ & $6 / 6$ & $25.52 \pm 6.50$ & 0.15 \\
\hline $10 \% \mathrm{NJ}$ & $6 / 6$ & $20.04 \pm 5.04$ & $0.04^{*}$ \\
\hline $10 \% \mathrm{NJ}+$ heparin & $5 / 6$ & $16.05 \pm 5.02$ & $0.02^{*}$ \\
\hline
\end{tabular}

$\mathrm{t} / \mathrm{n}=$ thrombus number in 6 animals for each group. Values are reported as mean weight $\pm \mathrm{SD}$. Student $t$ test $(p<0.05$, significant, $\mathrm{p}<0.01$ very significant, $\mathrm{p}<0.001$ extremely significant). The thrombus was successfully induced by oxidative Fecl 3 on jugular vein compared with blank control [ $<<0.001]$. The thrombus weight in each pre-treated group was compared with Fecl3 group. The thrombus weight in heparin and 5\% TNJ pre-treatment groups did not show a significantly reduction, the thrombus weight in $10 \%$ TNJ pretreated group showed a significant reduction compared with positive control. The combination group had a possible additive reduction of thrombi weight $[\mathrm{p}=0.02]$ compared with $10 \% \mathrm{NJ}$ and heparin respectively.

The thrombus weight [30.68 $\pm 11.98 \mathrm{mg}]$ in positive control group was extremely significantly increased [ $p=0.001$ ] compared with $9.90 \pm 2.10 \mathrm{mg}$ in control. There was a significant reduction of the thrombus weight observed in $10 \% \mathrm{NJ}$ group although the number of thrombus was not significantly changed. The thrombus weight $[20.04 \pm 5.04 \mathrm{mg}]$ in this group was significantly reduced compared with positive control group [p $=0.04]$. It was thus used in the combination group of Phase 2 study to examine a possible additive and/or synergistic effect between NJ and heparin. The thrombus weight in heparin group had a slight reduction [24.72 $\mathrm{mg}, \mathrm{P}>0.05$ ] compared with positive control. The thrombus weight in the combination group of NJ plus heparin had a possible additive reduction efficacy [16.05 $\pm 5.02, \mathrm{p}=0.02]$ compared with positive control, there was $48 \%$ reduction. There was a $34.8 \%$ reduction in heparin group and $19.4 \%$ reduction in $10 \% \mathrm{NJ}$ group respectively. There was one animal without an occluded vein observed in the combination group. Hence, there was a possible additive effect of the antithrombotic effect between $\mathrm{NJ}$ and heparin.

The histopathological examination of the jugular thrombi was performed by an experienced pathologist. The results were shown in Figure 2.

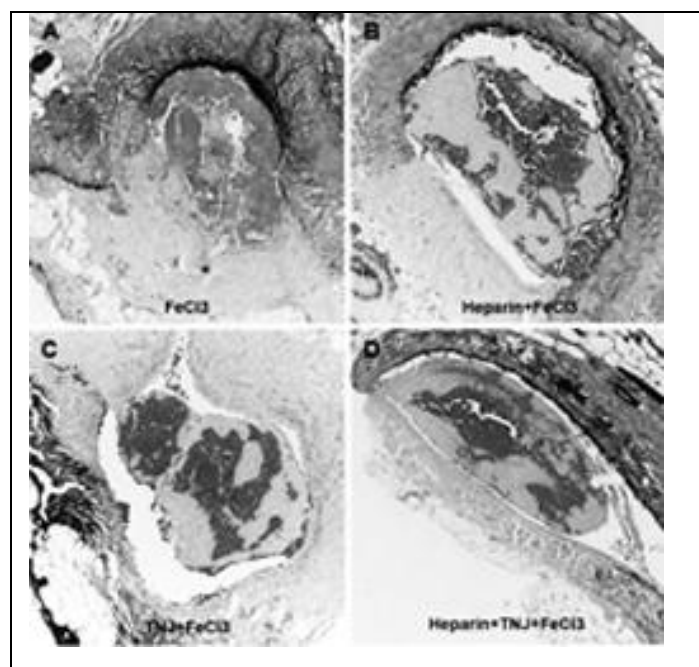

Figure 2 Anti-jugular vein thrombotic effect of heparin, TNJ, and their combination.

A. A thrombus induced by $\mathrm{FeCl} 3$ in positive control. Severe oxidative damage was observed on the venous wall and the density of thrombus is very high. There was no space observed between the thrombus and venous wall.

B. A thrombus in heparin $+\mathrm{feCl} 3$ group showed less oxidative damage, thrombus with low density, and there was a space between the thrombus and venous wall.

C. A thrombus in $10 \% \mathrm{TNJ}+\mathrm{Fecl} 3$ group showed much less oxidative damage, thrombus with lower density, and there is a larger space between thrombus and venous wall.

D. A thrombus in the combination group of Fecl3+TNJ+heparin showed a smaller thrombus, less oxidative damage, and a larger space between thrombus and venous wall. In summary, heparin and TNJ showed an anti-jugular vein thrombosis. An additive antithrombotic effect between heparin and TNJ was observed in the combination group. 
The jugular vein thrombus was successfully induced by oxidative $\mathrm{FeCl} 3$ in positive control group. The severe oxidative damage [color in black] was observed on the venous wall and the density of thrombus is very high without space observed between the thrombus and venous wall [A]. A thrombus in heparin $+\mathrm{FeCl} 3$ group showed less oxidative damage, thrombus with low density, and there was a space observed between the thrombus and venous wall [B]. A thrombus in $10 \% \mathrm{NJ}+\mathrm{Fecl} 3$ group showed much less oxidative damage, thrombus with lower density, and there is a larger space between thrombus and venous wall [C]. The strong anti-oxidative and antiinflammatory activities of NJ may play am important role on the inhibition of venous thrombosis. A thrombus in the combination group of NJ plus heparin showed a smaller thrombus, less oxidative damage, and a larger space between thrombus and venous wall [D]. In summary, heparin and NJ showed an anti-jugular vein thrombotic effect on the jugular vein thrombosis induced by oxidative ferric chloride in male SD rats. A possible additive antithrombotic effect of $\mathrm{NJ}$ with heparin was also observed in the combination group.

The impacts of NJ, heparin, and their combination regimen on aPTT and PT activities, as well as platelet count were determined to explore the possible mechanism for the anti-venous thrombotic effect of NJ, heparin, and the combination of NJ plus heparin. The data were shown in Table 2. In Table 2, there was a 3.5 fold of prolonged aPTT activity in heparin group [60.00 \pm $10.0 \mathrm{sec}, \mathrm{p}=0.002]$ compared with control [16.83 $\pm 4.8 \mathrm{sec}$ ]. A significant prolongation of aPTT in the $5 \% \mathrm{NJ}[34.24 \pm 9.6 \mathrm{sec}, \mathrm{p}=0.01]$ and a slight prolongation of aPTT in $10 \% \mathrm{NJ}[24.00 \pm$ $5.4 \mathrm{sec}, \mathrm{p}=0.06]$ groups compared with control. A significant prolongation of aPTT in the combination of $10 \% \mathrm{NJ}$ and heparin was also observed with a value of $40.00 \pm 4.5 \mathrm{sec}$ and $\mathrm{p}=$ 0.01, compared with control.

Table 2. Effect of NJ and heparin [300U/kg] on aPTT, PT, and platelet counts

\begin{tabular}{|l|ll|ll|cc|}
\hline Treatment & aPTT $[\mathrm{sec}]$ & $P$ value & PT $[\mathrm{sec}]$ & $P$ value & Platelet $\left[\mathrm{x} 10^{3} / \mu \mathrm{l}\right]$ & $P$ value \\
\hline Control & $16.83 \pm 4.9^{* *}$ & & $26.85 \pm 0.4$ & & $953.5 \pm 86^{*}$ & \\
\hline Heparin-only & $60.00 \pm 10.0$ & 0.002 & $36.52 \pm 3.0^{* *}$ & 0.01 & $775.7 \pm 84^{* *}$ & 0.06 \\
\hline $5 \% \mathrm{NJ}$ & $34.24 \pm 9.6$ & 0.01 & $25.15 \pm 0.6$ & 0.06 & $908.5 \pm 71^{*}$ & 0.52 \\
\hline $10 \% \mathrm{NJ}$ & $24.00 \pm 5.4$ & 0.06 & $28.18 \pm 3.3^{* *}$ & 0.21 & $987.6 \pm 95$ & 0.67 \\
\hline $10 \% \mathrm{NJ}+$ heparin & $40.00 \pm 4.5$ & 0.01 & $30.60 \pm 1.6$ & 0.04 & $943.4 \pm 67$ & 0.86 \\
\hline
\end{tabular}

$\mathrm{n}=6$, except indicated in table $* \mathrm{n}=4, * * \mathrm{n}=3$ respectively. aPTT=activated partial thromboplastin time, $\mathrm{PT}=$ prothrombin time.

The PT was very significantly prolonged in heparin group $[36.52 \pm 3.0 \mathrm{sec}, \mathrm{p}=0.01]$ and significant prolonged in the combination groups [30.60 $\pm 1.6 \mathrm{sec}, \mathrm{p}=0.04]$ compared with control $[26.85 \pm 0.4 \mathrm{sec}]$, respectively. There was only marginally significant prolonged in $5 \%$ NJ group [25.15 $\pm 0.6 \mathrm{sec}, \mathrm{p}=0.06]$ and no significant change in $10 \% \mathrm{NJ}$ group [28.18 $\pm 3.3 \mathrm{sec}$, $\mathrm{p}=0.21]$ compared with control group. Therefore, the prolongation of aPTT caused by heparin as well as NJ may be one of possible additive antithrombotic mechanisms. The prolongation of PT in combination group may be mainly caused by heparin since NJ did not show a significant impact on PT activity.

The platelet count was slightly reduced in heparin group [775.7 $\pm 84, \mathrm{p}=0.06]$ compared with control group $[953.5 \pm 86]$. There were no changes in $5 \% \mathrm{NJ}, 10 \% \mathrm{NJ}$, and combination groups compared with control group. The heparin-induced thrombocytopenia was not observed 
in combination group. Thus, NJ may help with thrombocytopenia caused by heparin. This needs a further study to have a conclusive result.

\section{Discussion:}

Thrombosis is a complex process involving changes in the vascular wall, platelet activation, adhesion and aggregation, the initiation and propagation of the coagulation cascade [34]. The standard therapy, heparin, offers an effective prophylaxis and treatment of deep vein thrombosis, but is limited by its side effects of an unpredictable anticoagulant effect due to variable nonspecific binding to plasma proteins, bleeding, heparin-induced thrombocytopenia, and osteopenia [35-36]. In this preliminary study, NJ was demonstrated to be a potential cost-effective and nontoxic alternative for DVT prophylaxis and adjuvant therapy.

The rat model described in the current study was designed for the study of the antithrombotic prophylactic effects of NJ, rather than treatment. The study indicates NJ at $10 \%$ concentration had an antithrombotic effect as shown with the significant reduction in thrombus weight. The combination group of $\mathrm{NJ}$ and heparin showed that $10 \% \mathrm{NJ}+$ heparin had a possible additive antithrombotic effect in ferric chloride induced jugular vein thrombosis model. Although there was a significant elevation of aPTT activity in the NJ groups, but no significant change in PT, it suggests a possible mechanism through another intrinsic pathway such as platelet function [37]. The platelet count was slightly decreased only in heparin group and there were no significant change in 5\% NJ, $10 \% \mathrm{NJ}$, as well as $\mathrm{NJ}$ plus heparin groups compared with control. NJ may provide more advantages over heparin because it is effective, natural, safe, and without thrombocytopenia [38]. A further study is definitely needed to examine the impacts of $\mathrm{NJ}$ on the platelet function such as platelet aggregation test as well as the impacts of NJ on the clotting factors.

The strong anti-oxidative and anti-inflammatory bioactivities of NJ may be responsible for the anti-venous thrombotic effect of NJ since fecl3-induced venous thrombosis are involved the oxidative damage and inflammatory responses caused by local application of Fecl3 on jugular vein. Pretreatment with $\mathrm{NJ}$ in rats may reduce the thrombosis induced by Fecl3. More specifically, the iridoids and phenolic compounds such as scopoletin, quercetin, kaempferol, and rutin, etc. existed in the $\mathrm{NJ}$ may be the major reason for the anti-venous thrombotic activity of NJ [39-44].

The latest data from our laboratory has demonstrated that $\mathrm{NJ}$ has a very strong anti-PE effect on collagen and epinephrine induced animal PE model. NJ also has a potentiating effect on the anti-platelet activity of aspirin using arachidonic acid, collagen, and ADP as inducers by using a Chrono-Log Platelet Aggregometer tests. NJ also has a potentiating anti-PE effect of aspirin on the animal PE model induced by collagen and epinephrine [45]. Thus, the current data generated in our laboratory strongly demonstrated that NJ may become an ideal, cost-effective, natural, and safe alternative on the prevention and treatment of VTE, DVT, and PE in humans. These data will be published in independent papers. We are very confident to predict that NJ may become a good natural blood thinner for the prevention and treatment of heart attack and ischemic stroke in humans. 


\section{Description of additional data files:}

We have recently investigated the impacts of $\mathrm{NJ}$ on the platelet aggregation and pulmonary embolism in ICR mice, the results indicated that NJ is a potent antiplatelet aggregation and antipulmonary embolism agent as well as it has an additive to synergistic effect on the anti-platelet and anti-pulmonary embolism activities with aspirin in ICR mice. Therefore, a warning should be given to patients who drink noni juice on the daily basis; their primary care physician should determine whether the amount of aspirin should be reduced.

\section{Conclusion:}

NJ has a strong antithrombotic effect on ferric chloride-induced jugular vein thrombosis model in rodents. NJ may offer an effective prophylaxis to DVT through the antioxidant and antiinflammatory activities. Previous studies showed NJ is a dual anti-inflammatory analgesic agent that improves the symptoms and the QoL of Osteoarthritis patients through inhibiting Cox-1, Cox-2, and 5-LO, these bioactivities of NJ may also impact on the platelet function. A further study to explore the mechanism of the anti-thrombotic effect of $\mathrm{NJ}$ is definitely needed in near future. A further study is suggested to better evaluate its antithrombotic efficiency and mechanisms of action on venous thrombosis as well as artery thrombosis. NJ may become a costeffective antithrombotic dietary supplement if we could provide enough scientific evidence. This pilot study provides us a clue for the antithrombotic activity of NJ.

\section{List of abbreviations used}

$\mathrm{VTE}=$ Venous thromboembolism; PE=pulmonary embolism; DVT=deep vein thromboembolism; TNJ=Tahitain Noni ${ }^{\circledR}$ juice; $\mathrm{NJ}=$ noni juice; $\mathrm{SD}=$ Sprague-Dawley; aPTT=activated partial thromboplastin time; $\mathrm{PT}=$ prothrombin time; 5-LO=5-lypoxygenase; Cox = cyclooxygenase; $\mathrm{BRC}=$ Biologic Resource Committee.

\section{Competing interests:}

Dr. Wang ever received funding support from the Morinda Corporation for research related to Tahitian Noni. The others have no competing interests to report

\section{Authors' contributions:}

Funmi Ayanbule: She won a financial support for this project from the James Scholar Program of University of Illinois College of Medicine at Rockford. She wrote a grant proposal and carried out this project under the guidance of Dr. Mian-Ying Wang and Dr. Lin Peng. Fummi was the major researcher for this project. She chose Dr.Wang as her mentor and supervisor. Goudong Li: Dr. Li has confirmed the data of this study in his laboratory in P. R. China. Lin Peng: Taught and trained Funmi Ayanbule and Jacob Nowicki on surgical and animal experimental skills used in this project. He was their teacher, trainer, and a supervisor for this study. Jacob Nowicki: Jacob was a student of environmental science of State College of Illnois in Normal, IL. He was a summer program student and research assistant in Dr. Wang's laboratory. He joined this study as a research assistant for James Scholar Research project. Gary Anderson: He did pathological examination of jugular thrombi removed from animals for this study. Mian-Ying Wang: She 
was a principle investigator of Morinda citrifolia (noni) project in the Departemnt of Pathology, University of Illinois College of Medicine at Rockford. She was Funmi's mentor, and supervisor of this research project. She provided oversight and contributed fundamental conceptualization for the research and writing manuscript.

\section{Acknowledgements and Funding:}

This study was supported by "James Scholar Program" of University of Illinois College of Medicine at Rockford, IL" to recognize and honor the top 2\% outstanding medical students. Medical student, Funmi Ayanbule, won financial support for this study and completed this project under the guidance of Dr. Mian-Ying Wang and Dr. Lin Peng in Dr. Wang's Laboratory. We thank Dr. Richard Novak and Mrs. LaVerne Larson for their strong support, comments, and critical suggestions. We also thank Morinda Holding Inc for the donation of Tahitian Noni® juice and placebo. A special thanks to Mr. John Javaherian for his efforts on animal care.

\section{References:}

1. Knight KK, Wong J, Hauch O, Wygant G, Aguilar D, Ofman JJ [2005] Economic and utilization outcomes associated with choice of treatment for venous thromboembolism in hospitalized patients. Value Health 8:191-200.

2. Lankeit M, Konstantinides S. Mortality risk assessment and the role of thrombolysis in pulmonary embolism. Clin Chest Med. 2010 Dec;31[4]:759-69.

3. Niranjan A, Agarwal N, Agarwal T, Agarwal M. Deep vein thrombosis: review and update. J Indian Med Assoc. 2010 Apr;108[4]:248-51.

4. Denson K, Morgan D, Cunningham R, Nigliazzo A, Brackett D, Lane M, et al. [2007] Incidence of venous thromboembolism in patients with traumatic brain injury. Am J Surg 193:380-384.

5. Hirsh J, Anand SS, Halperin JL, Fuster V [2001]. Mechanism of action and pharmacology of unfractionated heparin. Arterioscler Thromb Vasc Biol 21:1094-096.

6. Paliwal R, Paliwal SR, Agrawal GP, Vyas SP. Recent advances in search of oral heparin therapeutics. Med Res Rev. 2011 Feb 1. doi: 10.1002/med.202174.

7. Jaffer AK, Amin AN, Brotman DJ, Deitelzweig SB, McKean SC, Spyropoulos AC. Prevention of venous thromboembolism in the hospitalized medical patient. Cleve Clin J Med. 2008 Apr;75 Suppl 3:S7-16.

8. Tapson VF, Humbert M [2006]. Incidence and prevalence of chronic thromboembolic pulmonary hypertension: from acute to chronic pulmonary embolism. Proc Am Thorac Soc 3:564-567.

9. Morris TA. Heparin and low molecular weight heparin: background and pharmacology. Clin Chest Med. 2003 Mar;24[1]:39-47. Review.

10. Gómez-Outes A, Suárez-Gea ML, Lecumberri R, Rocha E, Pozo-Hernández C, VargasCastrillón E. New parenteral anticoagulants in development. Ther Adv Cardiovasc Dis. 2011 Feb;5[1]:33-59.

11. Butt A, Aronow WS, Chandy D. Heparin-induced thrombocytopenia and thrombosis. Compr Ther. 2010;36:23-7. Review. 
12. Shiotani A, Kamada T, Manabe N, Imamura H, Haruma K. The risk factors for aspirin induced peptic ulcer. Nippon Rinsho. 2010 Nov;68[11]:2015-9. Review.

13. Gao R, Li X. Risk assessment and aspirin use in Asian and Western populations. Vasc Health Risk Manag. 2010 Oct 21;6:943-56. Review.

14. Markwardt F. Hirudin as alternative anticoagulant--a historical review. Semin Thromb Hemost. 2002 Oct;28[5]:405-14. Review.

15. Prisco D, Falciani M, Antonucci E, Gensini GF. Hirudins for prophylaxis and treatment of venous thromboembolism. Semin Thromb Hemost. 2001 Oct;27[5]:543-9. Review.

16. Neil Solomon: The Noni Phenomenon: Discover the powerful tropical healer that fights cancer, lowers high blood pressure and relieves chronic pain. Direct Source Publishing. ISBN 1-887988-87-7. 2000.

17. Potterat O, Hamburger M. Morinda citrifolia [Noni] fruit--phytochemistry, pharmacology, safety. Planta Med. 2007 Mar;73[3]:191-9.

18. Pawlus AD, Kinghorn DA. Review of the ethnobotany, chemistry, biological activity and safety of the botanical dietary supplement Morinda citrifolia [noni]. J Pharm Pharmacol. 2007 Dec;59[12]:1587-609. Review.

19. McClatchey W. From Polynesian healers to health food stores: changing perspectives of Morinda citrifolia [Rubiaceae]. Integr Cancer Ther. 2002 Jun;1[2]:110-20; Review.

20. Wang MY, West BJ, Jensen CJ, Nowicki D, Su C, Palu AK, et al. [2002]. Morinda citrifolia [noni]: a literature review and recent advances in Noni research. Acta Pharmacol Sin 23:1127-1141.

21. Ayanbule F, Wang MY, Peng L, Nowicki J, Anderson G, Nowicki D. Antithrombotic effect of Morinda citrifolia [Noni] fruit juice on the Jugular Vein thrombosis induced by ferric chloride in male adult SD rats. Arterioscler. Thromb. Vasc. Biol. 2006; 26.

22. Wang MY, Su C. Cancer preventive effect of Morinda citrifolia [Noni]. Ann N Y Acad Sci. 2001 Dec;952:161-8.

23. Wang MY, Lutfiyya MN, Weidenbacher-Hoper V, Anderson G, Su CX, West BJ. Antioxidant activity of noni juice in heavy smokers. Chem Cent J. 2009 Oct 6;3:13.

24. Wang MY, Nowicki D, Anderson G, Jensen J, West B. Liver protective effects of Morinda citrifolia [Noni]. Plant Foods Hum Nutr. 2008 Jun;63[2]:59-63. Epub 2008 Mar 4.

25. Wang MY, Cheerva A, Su C, Jensen JC, Nowicki D, Anderson G, et al.[2002] Protective effect of Morinda citrifolia [Noni] on plasma SAR and LPO in current smokers. XI Biennial Meeting of the Society for Free Radical Research International; 2002 July 1620; Paris, France.

26. Muto J, Hosung L, Uwaya A, Isami F, Ohno M, Mikami T. Morinda citrifolia fruit reduces stress-induced impairment of cognitive function accompanied by vasculature improvement in mice. Physiol Behav. 2010 Sep 1;101(2):211-7.

27. Su C, Wang MY, Nowicki D, Jensen J, Anderson G [2001] A new selective COX-2 inhibitor: Morinda citrifolia [NONI]. Eicosanoids and other bioactive lipids in cancer, inflammation and related diseases. Poster presented at: 7th Annual Conference; 2001 Oct 14-17; Nashville, TN. 
28. Deng S, Palu K, West BJ, Su CX, Zhou BN, Jensen JC. Lipoxygenase inhibitory constituents of the fruits of noni [Morinda citrifolia] collected in Tahiti. J Nat Prod. 2007 May;70[5]:859-62.

29. Basar S, Uhlenhut K, Högger P, Schöne F, Westendorf J. Analgesic and antiinflammatory activity of Morinda citrifolia L. [Noni] fruit. Phytother Res. 2010 Jan;24[1]:38-42.

30. Day MS, Jennifer L. Reeve JL, Myers DD, Fay WP. Murine thrombosis models. Thromb Haemost 2004; 92: 486-94.

31. European Commission Health and Consumer Protection Directorate-general Directorate C - Scientific Opinions C2 - Management of scientific committees; scientific cooperation and networks. Scientific Committee on Food SCF/CS/NF/DOS/18 ADD 2 Final 11 December 2002.

32. Surin WR, Prakash P, Barthwal MK, Dikshit M. Optimization of ferric chloride induced thrombosis model in rats: effect of anti-platelet and anti-coagulant drugs. J Pharmacol Toxicol Methods. 2010 May-Jun;61[3]:287-91.

33. Parry BW. Laboratory evaluation of hemorrhagic coagulopathies in small animal practice. Vet Clin North Am Small Anim Pract. 1989 Jul;19[4]:729-42.

34. Kuntić V, Filipović I, Vujić Z. Effects of Rutin and Hesperidin and Their Al[III] and $\mathrm{Cu}[\mathrm{II}]$ Complexes on in Vitro Plasma Coagulation Assays. Molecules. 2011 Feb 7;16[2]:1378-88.

35. Parakh R, Kakkar VV, Kakkar AK [2007]. Venous Thromboembolism [VTE]. Core Study Group. Management of venous thromboembolism. J Assoc Physicians India 55:4970.

36. Bewick V, Cheek L, Ball J. Statistics review 9: one-way analysis of variance. Crit Care. 2004 Apr;8[2]:130-6.

37. Bounameaux H, Perrier A, Righini M. Diagnosis of venous thromboembolism: an update. Vasc Med. 2010 Oct;15[5]:399-406. Review.

38. Mattioli AV [2006] Heparin-induced thrombocytopenia: implications for cardiologist. G Ital Cardiol [Rome] 7:675-683.

39. Castelli R, Cassinerio E, Cappellini MD, Porro F, Graziadei G, Fabris F. Heparin induced thrombocytopenia: pathogenetic, clinical, diagnostic and therapeutic aspects. Cardiovasc Hematol Disord Drug Targets. 2007 Sep;7[3]:153-62. Review.

40. Pilsczek FH, Rifkin WD, Walerstein S [2005]. Overuse of prothrombin and partial thromboplastin coagulation tests in medical inpatients. Heart Lung 34:402-405.

41. Axelrod DA, Wakefield TW. Future directions in antithrombotic therapy: emphasis on venous thromboembolism. J Am Coll Surg. 2001 May;192[5]:641-51. Review.

42. Thani W, Vallisuta O, Siripong P, Ruangwises N. Anti-proliferative and antioxidative activities of Thai noni/Yor [Morinda citrifolia Linn.] leaf extract. Southeast Asian J Trop Med Public Health. 2010 Mar;41[2]:482-9.

43. Okusada K, Nakamoto K, Nishida M, Fujita-Hamabe W, Kamiya K, Mizushina Y, et al. The antinociceptive and anti-inflammatory action of the $\mathrm{CHCl} 3$-soluble phase and its 
main active component, damnacanthal, isolated from the root of Morinda citrifolia. Biol Pharm Bull. 2011;34[1]:103-7.

44. Wang MY, Lutfiyya MN, Weidenbacher-Hoper V, Peng L, Lipsky MS, Anderson G. Morinda citrifolia L. [noni] improves the Quality of Life [QoL] in adults with Osteoarthritis. Functinal Foods in Health and Disease 2011, Volume 2 [10 February 2011]

45. Deng S, West BJ, Palu K, Jensen CJ. Determination and comparative analysis of major iridoids in different parts and cultivation sources of Morinda citrifolia. Phytochem Anal. 2011 Jan-Feb;22[1]:26-30.

46. Dinda B, Chowdhury DR, Mohanta BC. Naturally occurring iridoids, secoiridoids and their bioactivity. An updated review, part 3. Chem Pharm Bull [Tokyo]. 2009 Aug;57[8]:765-96. Review.

47. Dussossoy E, Brat P, Bony E, Boudard F, Poucheret P, Mertz C, Giaimis J, Michel A. Characterization, anti-oxidative and anti-inflammatory effects of Costa Rican noni juice [Morinda citrifolia L.]. J Ethnopharmacol. 2011 Jan 7;133[1]:108-15.

48. Wang MY, Peng L, Deng SX, Yin WP, Ayanbule F, Nowicki J, Westin B, Smith B, Chai J, Haun J, Nowicki D, Anderson G. Morinda citrifolia [Noni] Challenges Aspirin: analgesic, anti-inflammatory, anti-thrombosis, anti-platelet, and gastro-intestinal protective activities of noni juice in laboratory rodents". The proceeding of the 8th International Functional Food: P231-235. March, 2011. University of Nevada in LasVegas, USA. 